\title{
Respiratory Conditions Associated with Tracheobronchomegaly (Mounier-Kuhn Syndrome): A Study of Seventeen Cases
}

\author{
Pierre Schmitt ${ }^{\mathrm{a}}$ Levent Dalar ${ }^{j}$ Stéphane Jouneau ${ }^{\mathrm{c}}$ Bénédicte Toublanc ${ }^{\mathrm{d}}$ \\ Juliette Camuset ${ }^{\mathrm{e}}$ Gérard Chatte $^{\mathrm{f}}$ Laurent Cellering $^{\mathrm{g}}$ Hervé Dutau $^{\mathrm{h}}$ \\ Stéphane Sanchez ${ }^{b}$ Maxime Sauvage ${ }^{i}$ Jean-Michel Vergnon ${ }^{i}$ Sandra Dury $^{\mathrm{a}}$ \\ Gaetan Deslée $^{\mathrm{a}}$ François Lebargy ${ }^{\mathrm{a}}$ Groupe d'Endoscopie de Langue Française \\ (GELF)

\begin{abstract}
a Department of Respiratory Medicine, University Hospital Maison Blanche, and ${ }^{\mathrm{b}}$ Department of Medical Research, University Hospital, Reims, 'Department of Respiratory Medicine, University Hospital Pontchaillou, Rennes 1 University, Rennes, ${ }^{d}$ Department of Critical Care and Respiratory Medicine, University Hospital Sud d'Amiens,

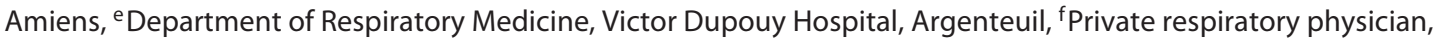
Caluire-et-Cuire, ${ }^{9}$ Department of Respiratory Medicine, University Hospital Nord Laënnec, Nantes, ${ }^{\mathrm{h}}$ Department of Thoracic Oncology, Pleural Diseases and Interventional Pulmonology, Hôpital Nord de Marseille, Marseille, and 'Department of Respiratory Medicine, University Hospital Nord, Saint-Étienne, France; ${ }^{j}$ Clinic of 7th Chest Diseases, Yedikule Chest Diseases and Chest Surgery Training and Research Hospital, Istanbul, Turkey
\end{abstract}

\section{Key Words}

Tracheobronchomegaly · Mounier-Kuhn syndrome ·

Bronchiectasis · Stenting

\begin{abstract}
Background: Mounier-Kuhn syndrome (MKS) is a rare disorder characterized by enlargement of the trachea and main bronchi and associated with recurrent respiratory tract infections. Objective: This multicenter, retrospective study was carried out to describe respiratory conditions associated with tracheobronchomegaly. Methods: Nine institutions involved in the 'Groupe d'Endoscopie de Langue Française' (GELF) participated in this study. A standard form was used to record patient characteristics, treatments and follow-up from medical charts. Results: Seventeen patients, 53\% male,
\end{abstract}

aged $58 \pm 18$ years at diagnosis were included. Recurrent infections revealed MKS in $88 \%$ of cases. Main comorbid conditions were diffuse bronchiectasis in $88 \%$ of patients and tracheobronchomalacia in $67 \%$ of cases. The exacerbation rate was 1.5 exacerbations/patient/year. The main non-respiratory morbid condition was gastroesophageal reflux disease in $29 \%$ of cases. Interventional bronchoscopy was performed in seven patients $(41 \%)$, consisting of laser $(n=2)$ and tracheal stenting $(n=5)$. Complications related to stents were observed in $80 \%$ of cases with a mean stent duration of 8 months. Four deaths, including three due to respiratory causes, occurred during follow-up. Conclusions: This is the largest series of MKS reported in the literature, showing that bronchiectasis and tracheobronchomalacia are the main associated morbid conditions that constitute a challenge for treatment.

\section{KARGER}

E-Mail karger@karger.com www.karger.com/res
(C) 2016 S. Karger AG, Basel

0025-7931/16/0914-0281\$39.50/0
François Lebargy, MD, PhD

Department of Respiratory Medicine University Hospital Maison Blanche 45 rue Cognacq-Jay, FR-51100 Reims (France)

E-Mail flebargy@chu-reims.fr 


\section{Introduction}

In 1932, Mounier-Kuhn [1] reported the case of a 42-year-old man with a history of recurrent respiratory tract infections and tracheobronchomegaly (TBM) on Lipiodol bronchography. Similar cases were subsequently reported and were therefore referred to as MounierKuhn syndrome (MKS) in honor of the author who had described the first case. With growing numbers of reported cases, various degrees of symptoms and conditions associated with TBM were observed. In 1962, Katz et al. [2] published a comprehensive review of TBM and referred to this condition by the eponym MKS. TBM and MKS are therefore both acceptable terms to describe the same entity [3-6]. The diagnosis is based on abnormally increased anteroposterior and/or transverse diameters of the trachea. TBM is considered to be a congenital disorder, but several reports suggest that TBM could be an acquired condition especially when associated with inflammatory processes affecting the trachea or bronchi, such as cystic fibrosis (CF) [7] or lung fibrosis [8].

Interestingly, no study has focused on respiratory disorders associated with MKS. The present study was therefore conducted to describe respiratory conditions associated with MKS and their management, which constitutes a challenge for pulmonologists.

\section{Methods}

\section{Study Design}

The study was conducted by the 'Groupe d'Endoscopie de Langue Française' (GELF). All centers were contacted by e-mail to identify adult patients with a diagnosis of MKS. All cases were diagnosed as TBM/MKS on the basis of enlargement of the trachea on chest CT scan. Tracheomegaly was defined on chest CT scan as a tracheal diameter greater than the normal mean diameter +3 standard deviations [9]. In practice, TBM was considered when transverse and/or sagittal diameters exceeded 21 and $25 \mathrm{~mm}$, respectively, in females and 25 and $27 \mathrm{~mm}$, respectively, in men [3, 5].

A standard form was used to record patient characteristics from medical charts. Demographic data, pulmonary symptoms, pulmonary function test results, bronchoscopic findings, and bacteriological findings were recorded. All measurements were performed on CT scan with lung windows rather than soft tissue windows to obtain better definition of the interface between the airway lumen and airway wall [10]. Measurements were performed $1 \mathrm{~cm}$ above the apex of the aortic arch. Diameters were calculated using mean transverse and sagittal diameters, determined by two independent investigators (P.S., F.L.). Note that a difference of no more than $2 \mathrm{~mm}$ was observed between the two investigators for all diameters measured.

Symptomatic and specific treatments were recorded, together with the duration of clinical follow-up.
Table 1. Demographic characteristics, presenting complaints and clinical characteristics of the 17 patients

\begin{tabular}{|c|c|}
\hline \multicolumn{2}{|l|}{ Demographic characteristics } \\
\hline Age at diagnosis, years & $58 \pm 18(3-82)$ \\
\hline Male & $9(53 \%)$ \\
\hline BMI & $22 \pm 6(15-36)$ \\
\hline \multicolumn{2}{|l|}{ Smoking status } \\
\hline Current smokers & $1(6 \%)$ \\
\hline Ex-smokers & $8(47 \%)$ \\
\hline Pack-years & $36 \pm 26(10-90)$ \\
\hline \multicolumn{2}{|l|}{ Presenting complaints } \\
\hline Infection & $15(88 \%)$ \\
\hline Pneumonia & $4(24 \%)$ \\
\hline Bronchitis & $14(82 \%)$ \\
\hline Chronic cough & $10(59 \%)$ \\
\hline Dyspnea & $11(65 \%)$ \\
\hline Hemoptysis & $3(18 \%)$ \\
\hline Failure of tracheal intubation & $1(6 \%)$ \\
\hline Spontaneous bronchial rupture & $1(6 \%)$ \\
\hline Fortuitous & $1(6 \%)$ \\
\hline \multicolumn{2}{|l|}{ Clinical characteristics } \\
\hline Time from symptoms to diagnosis, months & $54 \pm 57(1-228)$ \\
\hline \multicolumn{2}{|l|}{ Pulmonary function tests } \\
\hline FVC (\% predicted) & $81 \pm 25(29-128)$ \\
\hline $\mathrm{FEV}_{1}$ (\% predicted) & $64 \pm 24(30-117)$ \\
\hline $\mathrm{FEV}_{1} / \mathrm{FVC}$ ratio $<0.7$ & $9(53 \%)$ \\
\hline$\Delta \mathrm{FEV}_{1}>200 \mathrm{ml}$ & $2(12 \%)$ \\
\hline \multicolumn{2}{|l|}{ Blood gases on room air ${ }^{1}$} \\
\hline $\mathrm{PaCO}_{2}, \mathrm{~mm} \mathrm{Hg}$ & $41 \pm 7(30-54)$ \\
\hline $\mathrm{PaO}_{2}, \mathrm{~mm} \mathrm{Hg}$ & $71 \pm 14(50-99)$ \\
\hline \multicolumn{2}{|c|}{$\begin{array}{l}\text { Values are expressed as mean } \pm \text { standard deviation (range) or number of } \\
\text { patients }(\%) \text {. } \\
\text { BMI }=\text { Body mass index; } \mathrm{FVC}=\text { forced vital capacity; } \mathrm{FEV}_{1}=\text { forced } \\
\text { expiratory volume in the first second of expiration; } \triangle \mathrm{FEV} \mathrm{F}_{1}>200 \mathrm{ml}=\mathrm{FEV}_{1} \\
\text { increase of }>200 \mathrm{ml} \text { after short-acting } \beta_{2} \text {-agonist inhalation; } \mathrm{PaCO}_{2}=\text { partial } \\
\text { pressure of carbon dioxide in arterial blood; } \mathrm{PaO}_{2}=\text { partial pressure of } \\
\text { oxygen in arterial blood. } \\
{ }^{1} \text { Data available for } 13 \text { patients. }\end{array}$} \\
\hline
\end{tabular}

\section{Statistical Analysis}

Data are expressed as mean \pm standard deviation or number as appropriate. Fisher's exact test and the Mann-Whitney test were used for comparisons. A p value $<0.05$ was considered significant. SPSS software 21.0 (SPSS Inc., Chicago, Ill., USA) was used for statistical analysis.

\section{Results}

\section{Patient Characteristics}

Seventeen adult patients were included, collected by nine centers between 1990 and 2013: Reims ( $n=5)$, Istanbul $(\mathrm{n}=3)$, Amiens $(\mathrm{n}=2)$, Rennes $(\mathrm{n}=2)$, Marseille $(\mathrm{n}=1)$, Caluire-et-Cuire $(\mathrm{n}=1)$, Saint-Étienne $(\mathrm{n}=1)$, Argenteuil $(n=1)$ and Nantes $(n=1)$. The demographic 


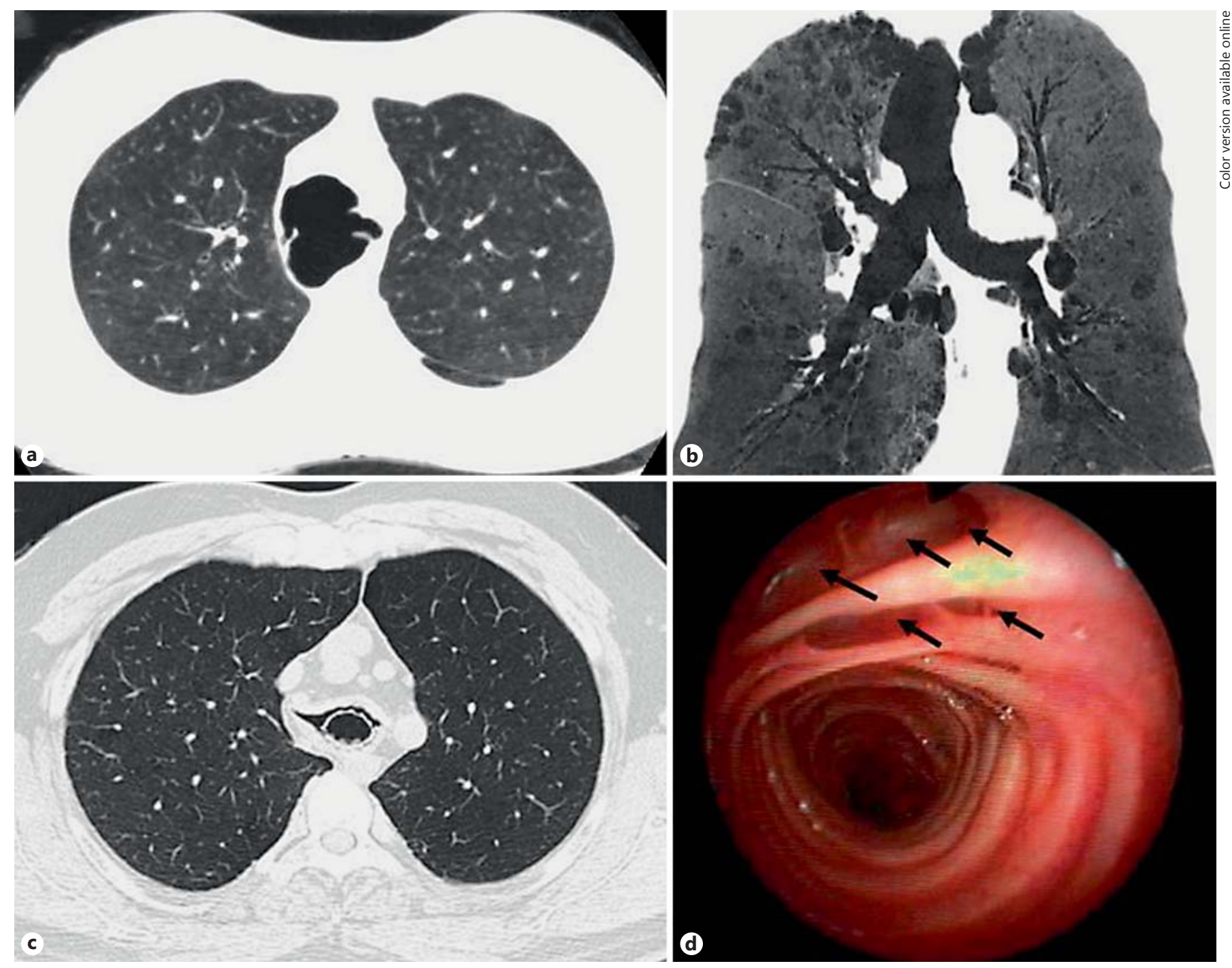

Fig. 1. CT scan and bronchoscopic findings in MKS. a CT axial slice showing tracheomegaly and diverticula. b CT transverse slice revealing emphysema in the upper lobes associated with TBM. c Stabilization of tracheomalacia by a stent. $\mathbf{d}$ Endoscopic view of the trachea and diverticula (arrows).

and clinical data as well as presenting complaints are summarized in table 1 . The main respiratory symptoms were respiratory infections (88\%), chronic cough (59\%) and dyspnea (65\%). Nine patients presented airflow limitation on pulmonary function tests. Two of them exhibited bronchial hyperreactivity.

\section{CT Scan and Bronchoscopic Findings}

On CT scan, the mean transverse tracheal diameter was $34.0 \pm 4.7 \mathrm{~mm}$ in males and $27.9 \pm 6.9 \mathrm{~mm}$ in females $(\mathrm{p}=0.02)$. The mean sagittal tracheal diameter was $22.8 \pm$ $5.4 \mathrm{~mm}$ in males and $30.0 \pm 9.9 \mathrm{~mm}$ in females $(\mathrm{p}=0.15)$.
The CT scan and bronchoscopic findings are detailed in table 2. Tracheal diverticula were detected on CT scan and fiberoptic bronchoscopy in nine patients (fig. 1a-d). Tracheomalacia, corresponding to $>50 \%$ narrowing of the anteroposterior tracheal diameter at forced expiration or voluntary cough [11], was detected by fiberoptic bronchoscopy in ten patients and extended to the main bronchi in nine of them. No correlation was found between tracheomalacia and airflow limitation $(\mathrm{p}=0.11)$. Emphysema was detected on CT scan in six patients (fig. 1b). No correlation was found between emphysema and tracheomalacia $(\mathrm{p}=0.61)$ or airflow limitation $(\mathrm{p}=0.66)$. 
Table 2. CT scan and bronchoscopic findings in the 17 patients

\begin{tabular}{lc}
\hline CT scan & \\
Bronchiectasis & $15(88 \%)$ \\
$\quad$ Diffuse & $15(88 \%)$ \\
$\quad$ Central and subsegmental & $14(93 \%)$ \\
$\quad$ Subsegmental only & $1(7 \%)$ \\
$\quad$ Localized & $0(0 \%)$ \\
Emphysema & $6(35 \%)$ \\
$\quad$ Centriacinar & $5(29 \%)$ \\
Paraseptal & $1(6 \%)$ \\
Panacinar & $0(0 \%)$ \\
Tracheal diverticula & $9(53 \%)$ \\
Condensation & $5(29 \%)$ \\
Tracheal thickening & $4(24 \%)$ \\
Mucoid impaction & $2(11 \%)$ \\
Air trapping & $1(6 \%)$ \\
\hline Bronchoscopy & \\
Malacia & \\
Tracheomalacia & \\
Bronchomalacia & $10(67 \%)$ \\
Diverticula & $9(53 \%)$ \\
Tracheal & $7(47 \%)$ \\
Main bronchi & $2(13 \%)$ \\
Bronchial suppuration & $10(67 \%)$ \\
Mucosal inflammation & $5(33 \%)$ \\
\hline
\end{tabular}

Values are expressed as number of patients (\%).

${ }^{1}$ Data available for 15 patients.

\section{Respiratory Comorbidities}

Tracheomegaly was associated with diffuse bronchiectasis in fifteen of the seventeen patients (tables 2, 3), involving central and distal bronchi in fourteen cases (fig. 1b). Fifteen patients presented a history of lower respiratory tract infections treated by short-course antibiotics. Bacteriological examinations revealed Pseudomonas aeruginosa $(\mathrm{n}=4)$, Stenotrophomonas maltophilia $(\mathrm{n}=1)$ and Serratia marcescens $(\mathrm{n}=1)$ infections. No Mycobacterium complex and Aspergillus infections were reported.

\section{Other Comorbidities}

Five patients complained of gastroesophageal reflux disease (GERD) and three of them presented hiatal hernia. All comorbid conditions are listed in table 3.

\section{Treatment and Follow-Up}

Symptomatic treatments included bronchodilators (11/17), inhaled corticosteroids (8/17), and oral steroids (1/17). Eight patients were treated by a combination of long-acting beta adrenoreceptor agonist and inhaled ste-
Table 3. Morbid conditions associated with MKS in the 17 patients

\begin{tabular}{lc}
\hline Respiratory comorbidities & \\
Bronchiectasis & $15(88 \%)$ \\
Tracheobronchomalacia $^{1}$ & $10(67 \%)$ \\
Emphysema & $6(35 \%)$ \\
Pulmonary hypertension & $2(12 \%)$ \\
Obstructive sleep disorders & $2(12 \%)$ \\
Fibrous histiocytoma & $1(6 \%)$ \\
\hline Non-respiratory comorbidities & $5(29 \%)$ \\
GERD & $3(18 \%)$ \\
Hiatal hernia & $2(12 \%)$ \\
Chronic heart failure & $1(6 \%)$ \\
Diabetes mellitus & $1(6 \%)$ \\
Anosmia & $1(6 \%)$ \\
Chronic sinusitis & $1(6 \%)$ \\
Dysmorphic syndrome & \\
\hline \multicolumn{2}{c}{ Values are expressed as number of patients $(\%)}$. \\
${ }^{1}$ Data available for 15 patients. ${ }^{2}$ Including dysmorphia, small \\
size and mental retardation.
\end{tabular}

roid (LABA/IS) (8/11), a long-acting muscarinic receptor antagonist alone $(\mathrm{n}=3)$ or in combination with LABA/IS $(\mathrm{n}=3)$, or with a short-acting beta-adrenergic or muscarinic agonist $(\mathrm{n}=5)$. Other treatments included chest physiotherapy (13/17), pulmonary rehabilitation (5/17), long-term oxygen therapy (4/17), and noninvasive ventilation for chronic hypercapnic respiratory failure $(n=3)$. Two of the four patients with chronic Pseudomonas infection were treated with long-term azithromycin.

Interventional rigid bronchoscopy was performed in seven patients, consisting of laser therapy $(n=2)$ (one case has been previously reported [6]) or tracheal stenting $(n=5)$ (fig. 1c). Complications of stenting were tracheal granulomas $(\mathrm{n}=2)$, stent migration $(\mathrm{n}=2)$, and bacterial infection $(n=2)$. The mean duration of stenting was 8 months (range $0.5-18$ months).

The mean follow-up was 6.3 years in fourteen patients. The infectious complication rate was 1.5 exacerbations/ patient/year. Four patients died during follow-up. Death was related to the respiratory condition in three patients, including acute respiratory failure $(\mathrm{n}=1)$ and end-stage respiratory failure $(n=2)$.

\section{Discussion}

Many studies have addressed the normal dimensions of the adult trachea, including postmortem, bronchographic, chest X-ray and CT scan studies $[2-3,9,10,12-$ 
14]. According to Breatnach et al. [9], tracheomegaly can be established when tracheal diameters on chest X-ray exceed the mean tracheal diameter of a normal population plus 3 standard deviations. More recently, a strong correlation was demonstrated between chest X-ray and CT scan to assess tracheal dimensions [12], but no consensus has been reached for bronchomegaly on CT scan. Breatnach et al.'s criteria were therefore used to include patients in this study. An in vivo morphometric study indicated that tracheal dimensions in adults are not influenced by age, weight, or stature, but only by gender, with greater diameters in men than in women [12]. In our series, the mean tracheal transverse diameter was greater in males than in females, but not the sagittal diameter, due to large interindividual variations. The mean age at diagnosis was $58 \pm 18$ years, similar to that reported in the literature, but the age of patients at the diagnosis of MKS varies considerably, from 18 months to 86 years [4]. A male predominance was reported in several systematic case reviews, but was not observed in our series, leading us to look for a particular etiology in our cases. However, in the absence of associated disorders such as solid tumors, T-cell lymphoma, endocrine diseases, end-stage renal disease, or amyloidosis, MKS is considered to be due to a congenital disorder [4].

Bronchiectasis is the most common comorbid condition associated with TBM $[3,4,10]$. In the present study, $88 \%$ of patients exhibited diffuse cylindrical bronchiectasis involving both central and subsegmental bronchi, similar to the rate reported in a previous series, in which six out ten MKS patients presented bronchiectasis on chest X-ray [3, 4, 6]. Various pathological abnormalities have been demonstrated in MKS, including absence of longitudinal elastic fibers, thinning of the muscularis mucosa, weakness of the cartilaginous and membranous portions of the trachea and main bronchi, and finally airway dilation [2]. The high rate of MKS-associated bronchiectasis therefore suggests that these pathological changes are not limited to the proximal airways, but could extend to the entire respiratory tract. However, it cannot be ruled out that bronchiectasis is the consequence of recurrent bronchial infections related to impaired mucociliary clearance in the trachea and main bronchi. In the literature and in the present study, most patients with TBM presented chronic cough and recurrent bronchial infections, suggesting that bronchiectasis constitutes a major component of the disease and its clinical expression [3]. Of note, exacerbation and $P$. aeruginosa colonization rates in our patients were similar to those reported in a larger series of non-CF bronchiectasis $[15,16]$. Due

Tracheobronchomegaly to the retrospective design of the study, we cannot rule out that hypogammaglobulinemia, CF, ciliary dyskinesia, or alpha-1-antitrypsin deficiency may have been missed, although none of these conditions were diagnosed on the basis of the patients' clinical charts.

The prevalence of airway dysfunction in TBM has not been clearly established, but the present study suggests that at least two-thirds of patients present tracheobronchomalacia. Inversely, previous studies have reported a non-fortuitous association of both disorders with a 5-12\% prevalence of TBM in the largest series of unselected tracheobronchomalacia $[17,18]$. In our series, tracheobronchomalacia was characterized by excessive dynamic airway collapse related to bowing of the posterior membranous wall into the trachea lumen rather than a true weakness of the cartilage structure (data not shown). This mechanism is presumed to cause central airway collapse and airflow obstruction, as suggested by improvement of symptoms, quality of life, and functional status after central airway stabilization by stenting and/or surgical tracheal splinting [17]. Nevertheless, a recent study demonstrated that airflow limitation in tracheobronchomalacia was not closely correlated with central airway collapse, but rather with peripheral airway narrowing related to associated bronchial disorders such as $\mathrm{CF}$, asthma, or chronic obstructive pulmonary disease (COPD) [19]. Interestingly, in the present study, one-half of the patients exhibited airflow limitation on pulmonary function testing and one-third presented signs of emphysema on CT scan. However, airway obstruction was not correlated with either tracheobronchomalacia or emphysema (data not shown).

Ancillary morbid associations include GERD, emphysema, and a constellation of diseases that have been considered to be chance associations (table 3). GERD is the most common non-respiratory condition associated with TBM, detected in $75 \%$ of cases in a previous study [20]. However, GERD has been demonstrated to be more prevalent in patients with obstructive lung diseases including COPD, CF, and asthma than in the general population [21-23]. In COPD, several factors have been suspected to facilitate GERD, including an increased gastroesophageal pressure gradient related to impairment of diaphragmatic function and/or decreased lower esophageal sphincter pressure induced by medications such as theophylline or $\beta_{2}$-agonists $[22,24]$, all conditions that may be present in MKS. Emphysema was found to be associated with TBM in one-third of patients in the present series. However, most patients had a history of smoking, which is known to be a major risk factor for emphysema. Interestingly, 
some patients with emphysema were light smokers or non-smokers and no correlation was found between airflow limitation, emphysema, and cigarette consumption. Our series, as well as other series $[3,4,6]$, found a higher prevalence of ever-smokers than in the general population ( $52 \mathrm{vs.} 30 \%$ ), raising the question on the role of smoking in the pathogenesis of MKS. Although some authors have suggested that tobacco smoking may induce chronic tracheal inflammation and could aggravate any preexisting congenital weakness of the trachea, the relationship between MKS and smoking has yet to be established [4].

Treatment remains primarily supportive and targets respiratory conditions associated with MKS. At steady state, the standard treatment of bronchiectasis consists of regular chest physiotherapy, influenza and pneumococcal vaccinations, and long-term azithromycin therapy for recurrent infections according to current guidelines [25]. Exacerbations require systemic antibiotic therapy and reinforcement of bronchodilation mainly using nebulized short-acting $\beta_{2}$-agonists $[25,26]$. In patients remaining symptomatic despite optimal medical treatment, airway stabilization has been proposed in order to reduce the consequences of tracheomalacia [17]. Silicone stents have been proposed as first-line treatment [17], but complications related to tracheal stenting have been reported in $90 \%$ of cases, leading to stent removal or replacement in many patients. Surgical tracheobronchoplasty, consisting of posterior tracheobronchial splinting, can therefore be considered in selected patients improved by primary short-term stenting [18]. This approach was proposed in a small series of MKS patients, demonstrating a trend to improvement of symptoms and outcome [18]. Paradoxically, stent migration was reported in only one patient, despite enlargement of the trachea [20]. In the present study, one-third of patients were considered for stenting due to persistent symptoms despite optimization of medical treatment. As reported in the literature, most of our patients developed stent-related complications, including obstruction, infection, granulation tissue, and migration, leading to stent removal or replacement $[17,18,20]$. Tracheobronchoplasty was not proposed to any of the patients of this series. One participating center [27] considered treating posterior collapse of the central airway with yttrium-aluminumperovskite laser with promising results. Double lung transplantation has been successfully performed in some cases of end-stage disease [28].

This study presents several notable limitations. First, the retrospective design is associated with missing data, especially laboratory investigations such as CF gene analysis or ciliary beat studies to rule out conditions associated with bronchiectasis. However, none of these conditions was diagnosed on the basis of the clinical charts in this cohort of patients. Second, the small number of patients due to the rarity of the disease may have failed to identify certain comorbidities. This study therefore does not allow evaluation of the efficacy of stenting on respiratory status and outcome.

In summary, MKS is a rare disease characterized by abnormal tracheal and bronchial enlargement. Diffuse bronchiectasis and tracheobronchomalacia are the main associated morbid conditions that constitute a challenge for treatment. Tracheal stabilization in MKS needs to be evaluated in a larger prospective series, but might be considered in patients with persistent symptoms after optimal medical treatment.

\section{Statement of Ethics}

This study was approved by the Reims University Hospital Institutional Review Board and the requirement for informed consent was waived.

\section{References}

1 Mounier-Kuhn P: Dilatation de la trachée: constatations radiographiques et bronchoscopiques. Lyon Med 1932;150:106-109.

2 Katz I, Levine M, Herman P: Tracheobronchiomegaly. The Mounier-Kuhn syndrome. Am J Roentgenol Radium Ther Nucl Med 1962;88:1084-1094.

-3 Woodring JH, Howard RS 2nd, Rehm SR: Congenital tracheobronchomegaly (Mounier-Kuhn syndrome): a report of 10 cases and review of the literature. J Thorac Imaging 1991;6:1-10.
4 Krustins E, Kravale Z, Buls A: Mounier-Kuhn syndrome or congenital tracheobronchomegaly: a literature review. Respir Med 2013;107: 1822-1828.

5 Fraser RS, Muller LN, Colman N, Paré PD: Mounier-Kuhn syndrome; in: Fraser and Paré's Diagnosis of Diseases of the Chest, ed 4. Philadelphia, Saunders, 1999, vol III, pp 2285-2287.
-6 Menon B, Aggarwal B, Iqbal A: MounierKuhn syndrome: report of 8 cases of tracheobronchomegaly with associated complications. South Med J 2008;101:83-87.

7 Griscom NT, Vawter GF, Stigol LC: Radiologic and pathologic abnormalities of the trachea in older patients with cystic fibrosis. AJR Am J Roentgenol 1987;148:691-693.

-8 Woodring JH, Barrett PA, Rehm SR, Nurenberg P: Acquired tracheomegaly in adults as a complication of diffuse pulmonary fibrosis. AJR Am J Roentgenol 1989;152:743-747. 
9 Breatnach E, Abbott GC, Fraser RG: Dimensions of the normal human trachea. AJR Am J Roentgenol 1984;142:903-906.

10 Roditi GH, Weir J: The association of tracheomegaly and bronchiectasis. Clin Radiol 1994;49:608-611.

11 Fraser RS, Muller LN, Colman N, Paré PD: Tracheomalacia; in: Fraser and Paré's Diagnosis of Diseases of the Chest, ed 4. Philadelphia, Saunders, 1999, vol III, pp 2042-2046.

12 Kamel KS, Lau G, Stringer MD: In vivo and in vitro morphometry of the human trachea. Clin Anat 2009;22:571-579.

13 Vock P, Spiegel T, Fram EK, Effmann EL: CT assessment of the adult intrathoracic cross section of the trachea. J Comput Assist Tomogr 1984;8:1076-1082.

14 Himalstein MR, Gallagher JC: Tracheobronchiomegaly. Ann Otol Rhinol Laryngol 1973; 82:223-227.

15 Wong C, Jayaram L, Karalus N, Eaton T, Tong C, Hockey H, Milne D, Fergusson W, Tuffery C, Sexton P, Storey L, Ashton T: Azithromycin for prevention of exacerbations in noncystic fibrosis bronchiectasis (EMBRACE): a randomised, double-blind, placebo-controlled trial. Lancet 2012;380:660-667.

16 Altenburg J, de Graaff CS, Stienstra Y, Sloos $\mathrm{JH}$, van Haren EH, Koppers RJ, van der Werf TS, Boersma WG: Effect of azithromycin maintenance treatment on infectious exacerbations among patients with non-cystic fibrosis bronchiectasis: the BAT randomized controlled trial. JAMA 2013;309:12511259.

17 Ernst A, Majid A, Feller-Kopman D, Guerrero J, Boiselle P, Loring SH, O'Donnell C, Decamp M, Herth FJ, Gangadharan S, Ashiku S: Airway stabilization with silicone stents for treating adult tracheobronchomalacia: a prospective observational study. Chest 2007;132: 609-616.

18 Majid A, Guerrero J, Gangadharan S, FellerKopman D, Boiselle P, DeCamp M, Ashiku S, Michaud G, Herth F, Ernst A: Tracheobronchoplasty for severe tracheobronchomalacia: a prospective outcome analysis. Chest 2008; 134:801-807.

19 Loring SH, O’Donnell CR, Feller-Kopman DJ, Ernst A: Central airway mechanics and flow limitation in acquired tracheobronchomalacia. Chest 2007;131:1118-1124.

20 Odell DD, Shah A, Gangadharan SP, Majid A, Michaud G, Herth F, Ernst A: Airway stenting and tracheobronchoplasty improve respiratory symptoms in Mounier-Kuhn syndrome. Chest 2011;140:867-873.

-21 García Rodríguez LA, Ruigómez A, MartínMerino E, Johansson S, Wallander MA: Relationship between gastroesophageal reflux disease and COPD in UK primary care. Chest 2008;134:1223-1230.

22 Kim J, Lee JH, Kim Y, Kim K, Oh YM, Yoo KH, Rhee CK, Yoon HK, Kim YS, Park YB,
Lee SW, Lee SD: Association between chronic obstructive pulmonary disease and gastroesophageal reflux disease: a national crosssectional cohort study. BMC Pulm Med 2013; 13:51.

23 Pauwels A, Blondeau K, Dupont LJ, Sifrim D: Mechanisms of increased gastroesophageal reflux in patients with cystic fibrosis. Am J Gastroenterol 2012;107:1346-1353.

24 Crowell MD, Zayat EN, Lacy BE, SchettlerDuncan A, Liu MC: The effects of an inhaled beta(2)-adrenergic agonist on lower esophageal function: a dose-response study. Chest 2001;120:1184-1189.

25 Pasteur MC, Bilton D, Hill AT; British Thoracic Society Bronchiectasis Non-CF Guideline Group: British Thoracic Society guideline for non-CF bronchiectasis. Thorax 2010; 65(suppl 1):i1-i58.

26 McShane PJ, Naureckas ET, Tino G, Strek ME: Non-cystic fibrosis bronchiectasis. Am J Respir Crit Care Med 2013;188:647-656.

27 Dutau H, Maldonado F, Breen DP, Colchen A: Endoscopic successful management of tracheobronchomalacia with laser: apropos of a Mounier-Kuhn syndrome. Eur J Cardiothorac Surg 2011;39:e186-e188.

28 Eberlein M, Geist LJ, Mullan BF, Parekh KR, Klesney-Tait JA: Long-term success after bilateral lung transplantation for MounierKuhn syndrome: a physiological description. Ann Am Thorac Soc 2013;10:534-537. 